Madushani, S.D.A., Seneviratne, L.D.I.P. and Ganeshu, P., 2019. Deciding on the consultancy fee for remeasurement contracts in the Sri Lankan construction industry. In: Sandanayake, Y.G., Gunatilake, S. and Waidyasekara, A. (eds). Proceedings of the $8^{\text {th }}$ World Construction Symposium, Colombo, Sri Lanka, 8-10 November 2019, pp. 231-238. DOI: doi.org/10.31705/WCS.2019.23. Available at: https://2019.ciobwcs.com/papers

\title{
DECIDING ON THE CONSULTANCY FEE FOR RE-MEASUREMENT CONTRACTS IN THE SRI LANKAN CONSTRUCTION INDUSTRY
}

\author{
S.D.A. Madushani ${ }^{1}$, L.D. Indunil P. Seneviratne ${ }^{2}$ and Pavithra Ganeshu ${ }^{3}$
}

\begin{abstract}
Construction industry is the necessary national backbone in developing countries. Consultants are the stakeholders who supplies objective and independent external service to the client. Consulting is gradually becoming a more standard service, price being the main factor in clients' contracting decision so consulting firms continually strives for cost reductions to provide a competitive pricing advantage. By conducting a comprehensive literature synthesis history about consulting fee decision criteria and IQSSL fee proposal were determined. Subsequently, expert interviews were conducted. Semi structured interviews and reviewing documents were used as data collection methods. Collected data was analysed using code based content analysis. It was revealed that, procurement methods and the consultancy fee have a relationship. Construction management contracts and the re-measurement contracts has the highest consultancy fee. There are number of factors to be considered when deciding on the consultancy fee. Findings suggested that independent quantity surveying consultancy fee is within the range between from $0.4 \%$ to $1.2 \%$ of the contract sum and IQSSL proposal has to accommodate number of improvements for it to be practiced in the Sri Lankan construction industry.
\end{abstract}

Keywords: Consortium Service Fee; Consultancy Fee; Independent Quantity Surveying Service Fee; Re-measurement Contracts.

\section{INTRODUCTION}

The consulting service plays an important role in world economy (Haverila, Bateman and Naumann, 2011). Molwus (2014) stated that Architect, Quantity Surveyor (QS), Engineer and Construction Manager are the consultants in the construction project. All construction professionals have important role in the construction process (Yadollahi et al., 2014).

According to Oyegoke et al. (2009), project procurement has a relationship with the overall quality of the project in terms of the economic, social and environmental wellbeing. Most commonly used traditional methods in Sri Lanka are lump sum method and re-measurement method (Rameezdeen and Silva, 2002). Re-measurement procurement method is the system with separation of design and the construction process (Cox and Townsend, 1998).

\footnotetext{
${ }^{1}$ Department of Building Economics, University of Moratuwa, Sri Lanka, Ayeshamadusapu123@gmail.com

2 Department of Building Economics, University of Moratuwa, Sri Lanka, indunil@uom.lk

${ }^{3}$ Department of Building Economics, University of Moratuwa, Sri Lanka, sunganesh21@gmail.com
} 
Consulting is gradually becoming a more standard service (Lassala, Carmona and Momparler, 2015). Moreover, price being the main factor in clients' contracting decision so consulting firms continually strive for cost reductions to provide a competitive pricing advantage. Furthermore, consultant reputation is especially important in consulting service industry, in which new assignments come largely through recommendations. Therefore, consulting fee deciding criteria is required for construction projects in the Sri Lankan construction industry.

Research on consultancy fee has been very minimal in the local as well as in the global context. Lassala et al. (2015) contends that higher level of client satisfaction denotes higher level of consultancy fee. Consultancy fee charges on daily basis but private sector clients demand lump sum price (Ozeroglu, 2014). Guideline for engineering consultancy fee is issued by the Institution of Engineers Sri Lanka (IESL). There is a guideline called professional fees for Quantity Surveying consultancy services published by the Institute of Quantity Surveyors Sri Lanka (IQSSL) for different types of projects and it has been implemented. There is no clear fee guideline to identify the consultancy fee in remeasurement contracts in Sri Lankan construction industry. Accordingly, the aim of the research was to identify consultancy fee for re-measurement contracts in the Sri Lankan construction industry.

\section{LITERATURE REVIEW}

\subsection{FACTORS TO BE CONSIDERED WHEN DECIDING ON THE CONSULTANCY FEE}

Lassala et al. (2016) stated that consulting firms use their qualification, capability, knowledge and creativity to enhance the value and customer satisfaction within the consulting firm. According to Ozeroglu (2014), price is not considered as the deciding factor however price is important at all times. In addition to that client expects the proper outcome for the fee paid. Moreover, these are the factors to be considered when deciding on the consultancy fee.

- The normal or going market rate for that particular type of work

- The fees charged by competitors

- If the "product or service" is new, we may have a "promotional" price to launch it

- The government, or a large company, may have norms for the payment of consultants and may not be prepared to go beyond these norms.

- The fee will have to be related to the image and status of the consultant in the market place

- The state of the development of the market for consultancy services, such as in Turkey where it is an emerging but not an established market

- The ability of the client to pay

- The value of the client as a potential long term client

- The workload of the consultancy company at the time of the proposal

- The potential for the use of the assignment as a training ground for younger less experienced consultants 


\subsection{History ON DECIDING ON THE CONSUltancy FeE}

These are the other methods adopted for payment for the consultants in the construction industry (The Institution of Engineers Sri Lanka [IESL], 2018).

- Man-month or time based

- Lump-sum

- Percentage

\subsection{IQSSL FeE PROPOSAL}

IQSSL fee proposal has been produced as a professional fees for Quantity Surveying consultancy services (Institute of Quantity Surveyors Sri Lanka [IQSSL], 2018). Furthermore, IQSSL identified the scope of Quantity Surveying consultancy services and computation of fees according to the building works and the civil engineering works. Moreover, building works are categorized into five types and civil engineering works are categorized into two types.

Table 1: Scale of fees for category $A$

\begin{tabular}{lllll}
\hline \multicolumn{1}{c}{$\begin{array}{c}\text { Total Cost of } \\
\text { Works }\end{array}$} & \multicolumn{3}{c}{ Fees Payable } \\
\cline { 2 - 5 } & \multicolumn{3}{c}{ Pre Contract } & \multicolumn{2}{c}{ Post Contract } \\
\hline $25 \mathrm{~m}$ and below & $1.20 \%$ & of Initial contract price & $0.80 \%$ & of value of work done \\
$26 \mathrm{~m}-50 \mathrm{~m}$ & $1.05 \%$ & of Initial contract price & $0.70 \%$ & of value of work done \\
$51 \mathrm{~m}-100 \mathrm{~m}$ & $0.90 \%$ & of Initial contract price & $0.60 \%$ & of value of work done \\
$101 \mathrm{~m}-175 \mathrm{~m}$ & $0.75 \%$ & of Initial contract price & $0.50 \%$ & of value of work done \\
$176 \mathrm{~m}-250 \mathrm{~m}$ & $0.60 \%$ & of Initial contract price & $0.40 \%$ & of value of work done \\
$251 \mathrm{~m}-350 \mathrm{~m}$ & $0.57 \%$ & of Initial contract price & $0.38 \%$ & of value of work done \\
$351 \mathrm{~m}-500 \mathrm{~m}$ & $0.48 \%$ & of Initial contract price & $0.32 \%$ & of value of work done \\
over $500 \mathrm{~m}$ & $0.45 \%$ & of Initial contract price & $0.30 \%$ & of value of work done \\
\hline
\end{tabular}

\section{METHODOLOGY}

Mixed research approach is a combination of the qualitative approach and the quantitative approach. The mixed approach was used in this research to eliminate the drawbacks of the qualitative approach and the quantitative approach. Due to unavailability of consultancy fee guideline based on the procurement method, a preliminary interview was carried out to collect quantitative data and expert interviews collected both qualitative and quantitative data.

The research study aimed to decide the consultancy fee for re-measurement contracts in the Sri Lankan construction industry, the whole population cannot be practically surveyed therefore the constraints of the time and the resources. Non random sample was selected for this survey from the industry experts who had experience in the independent quantity surveying service.

One of the most commonly used data collection technique is interviewing. Expert interviews were the main data collection technique in this research. Semi structured interview guideline was used to gather information from the interviewees. Six number of 
semi structured interviews were conducted. They were experts in the deciding on the independent quantity surveying service fee within the Sri Lankan construction industry. Semi structured interview guideline's data highly depend on the thoughts of the interviewees.

Table 2: Details of interviewees

\begin{tabular}{cccl}
\hline $\begin{array}{c}\text { Interviewee } \\
\text { No. }\end{array}$ & Designation & $\begin{array}{c}\text { Work experience } \\
\text { (years) }\end{array}$ & Organization \\
\hline 1 & Director & 25 & Pure Quantity Surveying service \\
2 & Director & 25 & Pure Quantity Surveying service \\
3 & Director & 40 & Pure Quantity Surveying service \\
4 & Senior QS & 15 & Pure Quantity Surveying service \\
5 & Director & 27 & Pure Quantity Surveying service \\
6 & Director & 40 & Pure Quantity Surveying service \\
\hline
\end{tabular}

Interviews were limited to six number since of the same findings repeated from the interviewees.

Data analysis derived the outcome of the research process. The results gathered from semi structured interviews were analysed using content analysis through NVivo 12 software. Mean weighted rating is used to evaluate the collected quantitative data from the expert interviews.

\subsection{CONTENT ANALYSIS}

Content analysis is the quantitative and qualitative data analysis method (Kondracki, Wellman and Amundson, 2002). Moreover, content analysis can be used to assess the word-based information from interviews and open-ended questionnaire survey questions.

\subsection{MEAN WEIGHTED RATING}

A mean weighted rating (adapted from Kothari, 2004) for each characteristic was computed using equation (01) to identify the impact of the factor to be considered when deciding on the consultancy service fee.

$$
\mu=\frac{\sum v_{i} x_{f i}}{n}
$$

Where; $\mathrm{V}_{\mathrm{i}}=$ Rating given by $\mathrm{i}^{\text {th }}$ respondent; $\mathrm{Fi}=$ Frequency of responses; $\mathrm{n}=$ Total number of respondents

\section{DATA ANALYSIS AND DISCUSSION}

\subsection{PURE QUANTITY SURVEYING FirM}

The respondents were experts in independent quantity surveying Consultancy service in the Sri Lankan construction industry.

\subsubsection{Importance of using Quantity Surveying Service}

These are the main reasons for using independent quantity surveying service in the Sri Lankan construction industry. 
- Value for money

- Proper cost data reporting system

- Client knows the budget from the inception

- Client will get the expert advice to procure the project

- Reduction of problems and disputes

- Can give alternative systems for very costly systems

- Enhance the economical way of doing the project without harming to the concept

- Proper evaluation of bid prices

- Cost control

- Value Engineering

- Quality assurance

- Contractor can get fair amount for variation

Effective quantity surveying service in a project will ensure successful management of a project from inception to completion and handover with best outcome in terms of time and cost. Monitoring the project will be easier with proper Quantity Surveying service. QS is providing his or her service to client, contractor to reduce cost of construction and maximizing the project value by minimizing wastage. This term is called as value for money. Proper cost data reporting system is useful for future projects to get the overall idea of the project. Independent quantity surveying consultancy service fee. Independent quantity surveying consultancy service fee is gradually increasing. These are the reasons for increasing of the independent quantity surveying consultancy service fee.

Reasons for increasing independent quantity surveying consultancy service fee:

- Understanding the importance of QS role in the construction industry

- It safeguards the client interest

- Most important person to do the finance management

- Client ready to pay

- Competition

- Demand fluctuation

- Independent Quantity Surveying service has established in the market

\subsubsection{Factors to be Considered when Deciding on the Independent Quantity Surveying Consultancy Service Fee}

According to findings shown in Figure 1, industry practitioners consider the current market rate as well as their reputation in the Sri Lankan construction industry to decide on the independent quantity surveying consultancy service fee for a project. Competitors' fee, long term customer relationship to the independent quantity surveying service, organization past know how on handling the client and preferences of the client were the other factors to be considered. Accordingly, the independent quantity surveying service fee can be calculated. Further, independent quantity surveying service consider the current workload and the available staff in the organization to take the decision. Project value, project duration, location of the project, nature of the project and relationship between the clients are the other highly placed factors when deciding on the independent quantity surveying fee. 


\begin{tabular}{|c|c|c|c|}
\hline 1 Name & Files & $\bar{\nabla}$ & References \\
\hline Factors to be considered when deciding on the Independent Quantity Surveying consultancy service fee & & 6 & 88 \\
\hline The normal or going market rate for that particular type of work & & 6 & 6 \\
\hline The fees charged by competitors & & 6 & 6 \\
\hline The fee will have to be related to the image and status of the consultant in the market place & & 6 & 6 \\
\hline The value of the client as a potential long term client & & 6 & 6 \\
\hline The workload of the consultant company at the time of the proposal & & 6 & 6 \\
\hline Project value & & 6 & 6 \\
\hline Project duration & & 6 & 6 \\
\hline Location of the project & & 6 & 6 \\
\hline Nature of the project & & 6 & 6 \\
\hline Relationship between the client & & 6 & 6 \\
\hline The government, or a large company, may have norms for the payment of consultants and may not & & 5 & 5 \\
\hline The potential for the use of the assignment as a training ground for younger less experienced consu & & 5 & 5 \\
\hline If the "product or service" is new, we may have a "promotional" price to launch it & & 4 & 4 \\
\hline The state of the development of the market for consultancy services, such as in Turkey where it is an & & 4 & 4 \\
\hline The ability of the client to pay & & 4 & 4 \\
\hline Business sustainability & & 3 & 3 \\
\hline Environmental factors & & 2 & 2 \\
\hline Professional liability & & 1 & 1 \\
\hline
\end{tabular}

Figure 1: Factors to be considered when deciding on the independent quantity surveying consultancy service fee

\subsubsection{Impact of Factors to be Considered when Deciding on the Independent Quantity Surveying Consultancy Service Fee}

Figure 2 represents the impact of the independent quantity surveying consultancy service fee factors to the decision. The factors identified by Ozeroglu (2014) was used for the ranking. Accordingly, the respondents identified "The value of the client as a potential long term client", "The fees charged by competitors" and "The workload of the consultant company at the time of the proposal" as the highly impact factors when deciding on the independent quantity surveying consultancy service fee for the re-measurement contracts for the Sri Lankan construction industry.

\subsubsection{Current Practice of Deciding on the Independent Quantity Surveying Consultancy Service Fee for Re-Measurement Contracts in the Sri Lankan Construction Industry}

The research findings indicate that the fee percentage is not less than $0.4 \%$ of the contract sum. The respondents indicated that the cost details of the past projects plus reasonable mark-up had been considered in the calculation for the independent quantity surveying consultancy service fee for re-measurement contracts. Maximum fee percentage was stated as $1.2 \%$ of the contract sum. Detailed costing had been used to determine the fee for the project. Findings suggested that independent quantity surveying consultancy fee within the range of $0.4 \%$ to $1.2 \%$ of the contract sum. It will vary from the organization 
to organization and will change according to the factors to be considered when calculating the fee.

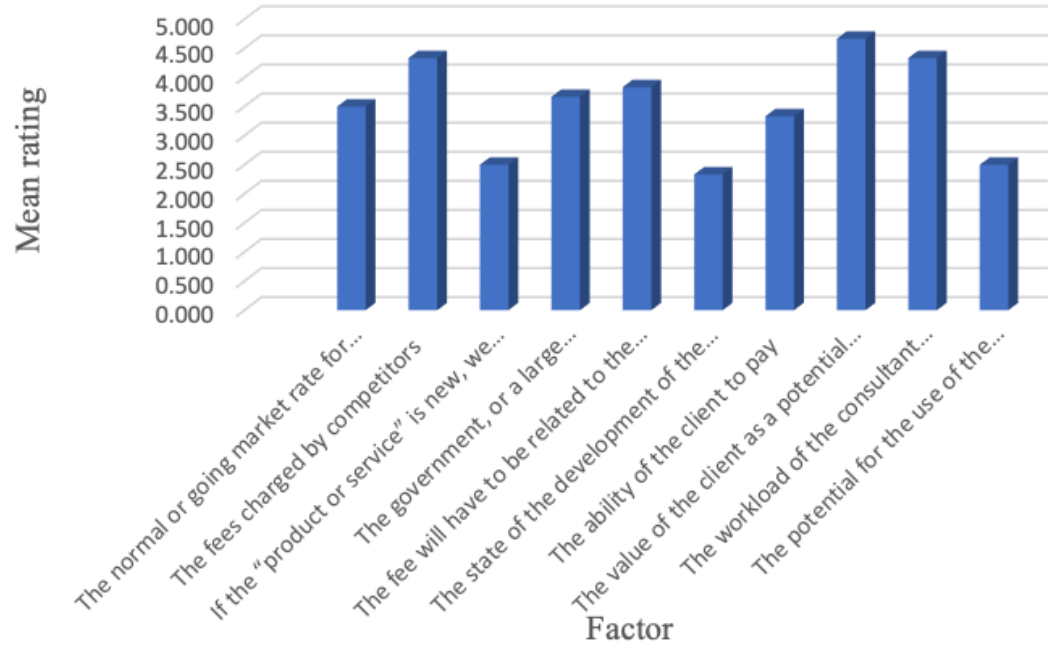

Figure 2: Impact of the factors to be considered when deciding on the Independent Quantity Surveying consultancy service fee

\subsubsection{Published IQSSL Proposal relating to the Independent Quantity Surveying Consultancy Service Fee}

IQSSL proposal attempts to find the standard fee guideline for independent quantity surveying consultancy service fee. However, according to the opinion of the respondents it will give guideline for the decision on the independent quantity surveying consultancy service fee.

\subsubsection{Improvements Proposed for the IQSSL Fee Proposal}

IQSSL fee proposal had been prepared for the traditional procurement system with Bill of Quantities and "measure and pay" payment methodology. The research established the need for guidelines for quoting fees for other type of procurement methods like integrated system, management oriented system and collaborative systems. Further, IQSSL fee proposal states the fee percentage for the different types of building projects. However according to the opinion of the respondents' fee percentage must be stated as a range. In addition, adjustment factors need to be proposed based on the nature of the construction, location of the project and specific details.

The research also found the importance of getting the constant feedback from the IQSSL members through a discussion forum established through the IQSSL web.

\section{CONCLUSIONS AND RECOMMENDATIONS}

Findings from the expert interviews demonstrated that quantity surveying service play a major role in a construction project to ensure the value for money. There are number of services are provided under the quantity surveying service. According to the opinion of the respondents it was revealed that construction management contracts and the remeasurement contracts have the highest independent quantity surveying consultancy service fees. Re-measurement contracts are popular therefore it is the traditional way of procuring for a long period in Sri Lanka. 
The normal or going market rate for that particular type of work, the fees charged by the competitors, the fee in relation to the image and status of the consultant in the market place, the value of the client as a potential long term client, the workload of the consultant company at the time of the proposal, project value, project duration, location of the project, nature of the project and relationship between the client are the most important factors when calculating and quoting the independent Quantity Surveying consultancy service fees for re-measurement contracts in the Sri Lankan construction industry. Further according to the opinion of the respondents IQSSL published fee proposal will only be a guideline for decision on the independent Quantity Surveying consultancy service fee. Findings suggested that Independent Quantity Surveying consultancy fee is within the range between from $0.4 \%$ to $1.2 \%$ of the contract sum and IQSSL proposal has to accommodate number of improvements to be effectively practiced in the Sri Lankan construction industry.

\section{REFERENCES}

Cox, A. and Townsend, M., 1998. Strategic Procurement in Construction: Towards Better Practice in Management of Construction Supply Chain. London: Thomas Telford.

Haverila, M., Bateman, E. R., and Naumann, E. R., 2011. The drivers of customer satisfaction in strategic consulting engagements a global study. Management Decision, 49(8), pp.1354-1370.

Institute of Quantity Surveyors Sri Lanka [IQSSL]., 2018. Professional fees for Quantity Surveying consultancy services. Available from: http://www.iqssl.lk/resources/qs-fee-scale.html

Kondracki, N., Wellman, N., and Amundson, D., 2002. Content analysis: Review of methods and their applications in nutrition education. Journal of Nutrition Education and Behaviour, 34(4), pp.224-230.

Kothari, C. R., 2004. Research methodology: Methods and techniques. New Delhi, India: New Age International (Pvt) Ltd.

Lassala, C., Carmona, P., and Momparler, A., 2015. Quality of consulting services and consulting fees. Journal of Business Research, 68(7), pp.1458-1462.

Lassala, C., Carmona, P., and Momparler, A., 2016. Alternative paths to high consulting fees: a fuzzy-set analysis. Journal of Business Research, 69(4), pp.1367-1371.

Molwus, J. J., 2014. Stakeholder management in construction projects: A life cycle based framework. (Doctoral thesis), Heriot Watt University.

Oyegoke, A. S., Dickinson, M., Khalfan, M. M., McDermott, P., and Rowlinson, S., 2009. Construction project procurement routes: an in-depth critique. International Journal of Managing Projects in Business, 2(3), pp.338-354.

Ozeroglu, A. I., 2014. Financial framework of consultancy services. Procedia - Social and Behavioral Sciences, 114, pp.787-793.

Rameezdeen, R., and Silva, S. D., (2002). Trends in construction procurement systems in Sri Lanka. BuiltEnvironment Sri Lanka, 2(1), pp.2-9.

The Institution of Engineers Sri Lanka [IESL]. (2018). IESL guideline structure for engineering consultancy fees. Sri Lanka.

Yadollahi, M., Mirghasemi, M., Zin, R. M., and Singh, B., 2014. Architect critical challenges as a project manager in construction projects: a case study. Advances in Civil Engineering, 2014, pp.1-15. 